\title{
Elements and evaluation system of key capacities of vocational college students under management horizon
}

\author{
Wu Xuehui, Liu Chundi \\ Shanghai University Of Engineering Science, china \\ *zifengwxh@126.com
}

Keywords: Management, core competency, evaluation system, Delphi

Abstract. Based on the summary of elements and evaluation of the core competences of vocational college students, the elements are defined from the sight of the connotation of management and indicators system are subdivided around the resource optimization and configuration management activities on the target for self-career. Combined with Delphi method, basic capability, adaptation ability and development ability are determined to be the fist-level indicators of the core competences of vocational students; learning ability, communication skills, information capabilities, relationship ability, collaboration, business ability, emotional ability, planning ability, innovation ability are the second-level indicators and 36 third-level indicators are selected. Recommendations are proposed such as setting goal-oriented, competency-based "theory and practice integration" curriculum, carrying out second classes through multi-carriers and multi-dimensional special psychological training activities.

Since the 1970s, core capabilities are widely studied, referred to people's basic ability in their careers in addition to the professional competence for posts, and are essential general abilities which can be migrated to engage in any occupation with universal applicability, widespread and persistent migration characteristics. With the rapid development of social economy and enrollment in higher education, vocational college students culturing quality becomes increasingly important to get students to develop core competency common in adapting career is an important way to enhance the quality of education for vocational college students. Decomposition of core competence elements and evaluation index system building for vocational college students is important for vocational college students core abilities.

\section{Analysis of relevant principles and philosophy of management}

Based on principles of management, management refers to activities organizations or individuals plan, organize, lead and control their resources effectively in certain circumstances by optimizing the configuration of related resources to effectively achieve organizational or personal goals. The key of management is efficient allocation of resources already had or likely to have focusing the goal. Types of resources can be divided into human, finance, material, information and relationships.

2. Definition and connotation of core competencies of vocational college students under the management horizon

\subsection{Summary of core competence of the vocational college students}

In 1974, Mei Martens who is the director of the German occupation of the labor market and vocational education institute first proposed the" core competencies "concept in the Report < Occupational Adaptability Overview > for the EU . Since the 1970s, with the burgeoning of British new occupation ideology, all sectors of the UK increased research on core competencies. " interpretation for British core skills policy and practice " jointly published by UK Department for Education and Skills, Learning and Skills Council, Qualifications and Curriculum Committee 
pointed that: the core skills are a series of universal basic skills helpful to education, work, lifelong learning and personal development success which is practical application skills not just for young people but also for adults.

Most of the existing concepts of core competence are based on the description of what core competencies are but lack of a clearly definition and summary for the pointing goal or object ,the process of obtaining of core competencies. Article will define core competencies from the above angle in management science sight.

\subsection{Definition of core competencies of vocational students under management horizon}

The culture of core competencies should be targeted on self-career development and optimize the allocation of acquired or possible available resources. Therefore, the article will define core competencies as abilities targeted on the goal of individual career development by optimizing the allocation and management of obtained or possible available resources. The development of core competencies is essentially a activity process carried out about their own career by planning, organizing, leading and controlling.

\section{Elements of core competencies analysis and evaluation system of vocational students}

\subsection{Summary of core competencies elements and evaluation system}

There has been certain research on factors and evaluation about core competencies home and abroad. In 1980s, British Business and Technical Education Commission (BTEC) divided professional competence into general ability and expertise.General capabilities include: self-care and self-discipline; communication and collaboration capabilities; ability to learn and develop; ability to collect and process information; ability to manage and complete the task; and emergency response capabilities; criticism and innovation ability and stamina and resistance to frustration ability. In 1991 US Department of Labor released SCANS report proposing that practitioners should have three basic qualities and five basic capabilities: ability of domination and rational use of resources, ability of obtaining and accessing information, ability to deal with interpersonal relationships, ability of using a variety of technologies and systematic analysis.

Occupational Skill Testing Center of China Labor and Social Security Ministry define eight core competencies: expression, number crunching, reform and innovation, self-improvement, work with others, problem solving, information processing, foreign language applications. Domestic related scholars divided professional core competencies into three factors including professional competence, methodology skills and social skills, which some scholars divide into basic ability, key competence and potential ability.

Each index system from past researches didn't include all aspects of core competencies due to the lack of a systematic perspective. This article will try to combine existing research results under the management science horizon to research factors and evaluation system from the perspective of career management and the acquisition and development of core competencies systematically.

\subsection{Elements analysis and index selection of core ability of vocational students}

According to the above definition, this article divides the core competencies of vocational students into three levels of nine areas, namely: basic skills (learning skills, communication skills, information capabilities, relationship capacity, collaboration capabilities, operational capacity), adaptive capacity (emotional competence), development capacity (planning, innovation) by literature reading and expert advice et cetera 。

Basic capabilities are the necessary skill factors which ensure vocational students step into jobs and do related occupations successfully; the adaptive abilities are the security and motivation factors to help vocational students confront job instability; development capacities are the decisive factors to determine the quality and acceleration of long-term sustainable development. 


\section{3 evaluation screening ideas with Delphi method}

According to Delphi, The article refers the screening index to 16 members including senior vocational educators, corporate senior management personnel and graduates to add and modify by "back to back" method. Each round experts can modify, delete or increase indicators, and the researchers distribute the summary to each expert for the next round of modifications. After three rounds of evaluation, researchers select more important indicators on the basis of the experts consideration (final selection of indicators are not more than 50, but less than 18), which will be scored by experts(scores from 1-5, respectively, representing very unimportant to very important), before calculating the scores of indexes to determine the index evaluation system ultimately.

3.4 specific constructing of core competence evaluation system of vocational students

After four rounds of expert advices and screening, each indicator of core competencies are ultimately determined. As shown in Table 1.

Table 1 Core competences evaluation system of vocational students

\begin{tabular}{|c|c|c|}
\hline First-level index & Second-level index & Third-level index \\
\hline \multirow[t]{24}{*}{ Basic capability } & \multirow[t]{3}{*}{ Learning ability } & knowledge acquisition and application ability \\
\hline & & Learning self-monitoring capability \\
\hline & & Learning resources management and application capabilities \\
\hline & \multirow[t]{3}{*}{ Communication ability } & Comprehension ability \\
\hline & & Language skills \\
\hline & & Listening skills \\
\hline & \multirow[t]{5}{*}{ Information capacity } & open-minded characteristic \\
\hline & & Information gathering capability \\
\hline & & Information integration capability \\
\hline & & Information analysis capability \\
\hline & & Decision-making capacity \\
\hline & \multirow[t]{4}{*}{ Relationship capacity } & Extraversion \\
\hline & & Social interaction extension ability \\
\hline & & Interpersonal skills \\
\hline & & relationships maintenance ability \\
\hline & \multirow[t]{4}{*}{ Collaboration capacity } & Compatibility \\
\hline & & Service awareness \\
\hline & & Teamwork ability \\
\hline & & Obedience \\
\hline & \multirow[t]{5}{*}{ Operation capacity } & Professional knowledge and skills \\
\hline & & Logical analysis capability \\
\hline & & Experience \\
\hline & & Resilience \\
\hline & & Responsibility \\
\hline \multirow[t]{5}{*}{ Adaptive capacity } & \multirow[t]{5}{*}{ Emotion Competence } & Suitability \\
\hline & & Empathy \\
\hline & & Emotion Stability \\
\hline & & Resistance to stress \\
\hline & & Self-motivated ability \\
\hline \multirow[t]{7}{*}{ Development capacity } & \multirow[t]{3}{*}{ Planning capacity } & Reasonable positioning assessment capability \\
\hline & & Objective decision-making capacity \\
\hline & & Process control and adjustment ability \\
\hline & \multirow[t]{4}{*}{ Innovation capacity } & Independence \\
\hline & & Confidence \\
\hline & & Imagination \\
\hline & & Integration ability \\
\hline
\end{tabular}

4 Suggestions for core competencies culturing of vocational training students

4.1 Target-oriented, competency-based " theory-practice integration" Curriculum

Basic skills training is the main goal and task of vocational training course system, in which learning ability, communication skills, information capabilities, relationship skills and collaboration 
capabilities should be cultured through a reasonable set of vocational courses and training segment consciously except operational capacity which belongs to the professional knowledge and skills levels, For example, the currently researched and applied "OTPAE" five-step training method include students ability culturing into the curriculum by "object-target- preparation - action evaluation" five steps which reflects the goal-oriented, task-driven idea. Competency-oriented "theory- practice integration" curriculum focusing on the core competencies of vocational students is a big trend in the future.

\subsection{Carry out second classes by carriers such as "study-practice collaboration," "knowing and practice classroom"}

In addition to the main role of the first class, for vocational students, practice- oriented and activity-oriented second classes on campus are also important carriers likely to be widely accepted to bring up their professional core competencies. "Study-practice cooperation" originated from the University of Waterloo in Canada, which allows students to be involved in internships in advance to train students better to become "quasi-professional people" using an study-practice alternate pattern; Shanghai University of Engineering Science has also explored the "knowing and practice classroom" and other effective carriers through which the students can practice with their questions and reflections on campus in cultural activities and social practices to train vocational core competencies by "learn by practice, think in practice, knowledge and practice syncretism" . The rest kinds of second class activities such as cultural activities on campus, various competitions, and many other forms of social practices are also important carriers of professional core competencies development.

\subsection{Carry out multi-dimensional special psychological training activities taking career planning as the main line}

The goal of core competencies development is around career planning, and the core competencies elements covered a wide range of social parts such as communication skills, relationship capabilities, collaboration and emotional abilities. One factor or several factors, of core competency elements can be trained through special designed activities such team psychological and behavioral training. And special activities. can be developed taking career planning as the main line such as career assessment, seminars, class meetings, career guidance, etc. to enhance the professional core competencies .

Acknowledgment: This work is supported by 2013 Special Fund Project for Shanghai Young Teachers' Training Assistance Scheme (ZZGJD12023).All support is gratefully acknowledged.

\section{References:}

[1] Yang Jing, $\mathrm{Xu}$ Weijun. professional capacity evaluation criteria building of vocational students [J]. Vocational Technical Education, 2012 (17): 18

[2] Li Yifan. elements and the evaluation system construction of core competence of vocational college students $[\mathrm{J}]$. Zhejiang Education Institute Journal, 2008 (3)

[3]Zhang Wei. empirical research on the professional core competencies of vocational students training model[J]. Education Forum, 2012 (8): 72-74

[4] Zeng Xuhua, Pi Hongqin, Li Fudong. comprehensive evaluation index system method discuss of professional abilities of vocational students [J] . Vocational Technical Education, 2012(17): 9-13.

[5] Wang Meiping, Jiang Yanfei. research on basic quality and professional competence training of vocational students by curriculum construction and development $[\mathrm{J}]$. Education and Career, 2012 (8): 116-117 